\title{
A crise da escola pública: o aprender a aprender
}

\author{
Regina Magalhães de Souza*
}

Resumo: Este trabalho teve como principal objetivo investigar que tipo de sujeito está sendo formado pela escola pública nos dias de hoje em que ocorrem profundas mudanças na cultura. A escola pública, em crise, ao mesmo tempo em que não tem conseguido efetivar um projeto educativo, também não tem preparado os jovens para o mercado de trabalho, nem transmitindo informações e conhecimentos tecnológicos, nem exercendo um papel de disciplinadora da mão-de-obra. Foram investigados dois estabelecimentos escolares públicos de ensino médio da capital paulista, onde os jovens alunos participaram de sessões de entrevistas coletivas e responderam a um questionário fechado. A educação escolar oferecida consistia apenas no desenvolvimento da habilidade de "aprender a aprender" que, em última instância, significa o desenvolvimento da capacidade de se adaptar a uma vida social cuja tônica é a ausência de autoridade, crise de valores e critérios.

Palavras-chave: educação; escola pública; ensino médio; juventude; cultura contemporânea.

- Professora da rede pública de ensino e douforanda em Sociologia pela Universidade de Sāo Paulo.

\section{Pressupostos, objetivos e procedimentos da pesquisa}

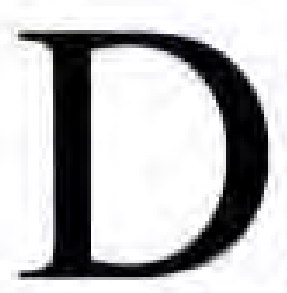

urante os meses de outubro e novembro de 1997 realizei uma pesquisa entre alunos da última série do ensino médio ( $3^{\circ}$ colegial) do período noturno de dois estabelecimentos escolares, mantidos pela administração estadual e localizados na Zona Norte da cidade de São Paulo. De início, 172 alunos responderam por escrito a um questionário e, em seguida, foram 
realizadas cinco sessões de entrevista, cada uma delas com grupos de oito alunos voluntários. A grande maioria dos participantes tinha entre 17 e 20 anos e estava inserida no mercado formal de trabalho (efetivamente trabalhando ou procurando emprego estavam 93,6\% dos pesquisados), cumprindo jornadas integrais em funções de escritório e de vendas dos setores de comércio e serviços e na área administrativa das indústrias.

É certo que os resultados da pesquisa realizada (em dois estabelecimentos escolares determinados, com base numa amostra não probabilistica de alunos pertencentes a determinado segmento juvenil, entre outros aspectos) não sejam estatisticamente generalizáveis para o conjunto do sistema escolar público do Brasil, nem mesmo do Estado ou da cidade de São Paulo. Tais resultados devem ser encarados como uma interpretação possível da situação em que se encontra a escola pública e uma contribuição ao debate e à reflexão sobre o assunto. Ainda que com tais limitações, creio que o trabalho realizado conseguiu detectar importantes aspectos do ambiente escolar e da vida juvenil, que merecem ser melhor compreendidos por meio de novos estudos e pesquisas. O texto a seguir deve ser lido tendo-se em mente essa observação.

O intuito do trabalho foi buscar, nos depoimentos dos jovens alunos, elementos que permitissem ampliar uma reflexão sobre a crise da escola pública nos dias de hoje, em que ocorrem mudanças significativas não apenas no âmbito da produção e do trabalho, mas numa esfera mais ampla, da própria cultura. Dessa forma, tratou-se de investigar que tipo de sujeito está sendo formado nessa escola - em crise - nesse momento de mutação cultural.

O suposto foi o de que a crise da escola extrapola os limites institucionais, inscrevendo-se num quadro mais geral de perda da autoridade no mundo contemporâneo. Diante da recusa dos adultos (insatisfeitos) em assumir a responsabilidade pelo mundo, a educação das crianças e jovens entra em crise (cf. ARENDT, 1992a). Em outras palavras: uma vez que os fundamentos da autoridade da escola - o respeito e a preservação do passado - estão cada vez mais ausentes hoje em dia, fica prejudicada a possibilidade de execução
A crise da escola pública: - aprender a aprender Regina Magalhäes de Souza 
A crise da escola pública: - aprender a aprender Regina Magalhäes de Souza de um projeto educativo que vise a transmissão da herança cultural às novas gerações.

Sem um projeto de educação, também ficam comprometidas as condições para a promoção de sujeitos críticos e autônomos no interior da escola; permanecem, por exemplo, apenas no texto legal as finalidades previstas pela LDB para o ensino médio (entre elas, a "preparação para a cidadania" ou "a formação ética e o desenvolvimento da autonomia intelectual e do pensamento crítico", conforme lei federal 9.394/96). Talvez com maior intensidade que nos outros níveis o ensino médio venha sofrendo, nas últimas décadas, as conseqüências da inexistência de um projeto educacional claro, transformando-se num curso sem identidade, que não prepara nem para o trabalho, nem para a universidade, nem para uma vida social democrática e responsável.

Os dois estabelecimentos escolares eram relativamente grandes (um deles, com mais de 2.000 alunos, e o outro, com mais de 3.000) e estavam localizados em pontos de fácil acesso, próximos a pólos comerciais da Zona Norte, de maneira que atendiam não só a população circunvizinha, mas também aquela residente em bairros mais distantes, "satélites", por assim dizer. Pode-se afirmar que, na hierarquia da rede, ambos os estabelecimentos ocupavam posição intermediária, gozando de certo prestígio, relativa qualidade de ensino e condições médias de funcionamento.

Não eram escolas centrais, de "nome", mas também não se localizavam nos limites da periferia da cidade, o que conduziu a um universo de pesquisa composto por jovens provenientes de camadas "intermediárias" da população: não totalmente "excluídos", mas tampouco efetivamente "incluídos" nos mundos do trabalho e do consumo, com uma garantia apenas parcial de direitos (sociais, civis, políticos). Jovens, portanto, que não representavam nenhuma espécie de ameaça ao sistema e que não tinham uma "visibilidade social", nem pelo traje ou comportamento geral, nem pela participação em manifestações coletivas ou em movimentos contestadores (como os jovens que fizeram parte do movimento estudantil, comumente tomado como "ideal" de mobilização juvenil), nem pela situação de precariedade 
e exclusão (como os "meninos de rua", freqüentemente lembrados pela mídia). O segmento juvenil considerado raras vezes foi objeto de produção acadêmica, quer na área da sociologia, quer na área de educação. Assim sendo, a perspectiva do "jovem aluno" de ensino médio da rede pública raramente - para não dizer nunca foi observada.

Até os anos 70, os estudos sociológicos sobre a juventude concebiam-na como agente de transformação numa sociedade em crise ou em processo de modernização, o que implicava classificar o comportamento juvenil em revolucionário, alienado ou conformista. A juventude era, pois, encarada como o segmento de classe que tinha uma tarefa a desempenhar no sentido da mudança social. Embora, a partir dos anos 80, uma outra perspectiva de análise - a da "cultura juvenil" - tenha sido incorporada pelos estudos sociológicos, o tema da ação política continuou presente em alguns trabalhos que tentaram explicar o comportamento (ora considerado "apático", ora considerado "inovador") das novas gerações diante das instituições e dos meios de participação política tradicionais.

Embora o tema da ação política não tenha sido diretamente abordado no trabalho realizado, que se centrou nas percepções juvenis sobre a escola e/ou decorrentes da vida escolar, o conhecimento, ainda que rudimentar, da subjetividade desses jovens determinados permitiu delinear um tipo de conduta social dominante não só entre eles, mas possivelmente em toda a sociedade nos dias de hoje. Em meio às mutações da cultura contemporânea, parece que a juventude continua sendo a categoria social sobre a qual se infletem as mudanças. Por outro lado, podese afirmar que o sentido da ação dos jovens pesquisados era o da inserção social, o que não significava, no entanto, aceitação passiva das regras sociais, mas dependia da operação de um determinado mecanismo de adaptação que identifiquei como "aprender a aprender".
A crise da escola pública:

- aprender a aprender

Regina Magalhâes de Souza 
A crise da escola pública: - aprender a aprender Regina Magalhāes de Souza

\section{Noções e práticas dos jovens alunos}

Os depoimentos dos entrevistados enfatizaram as idéias de que os elementos essenciais da vivência juvenil são a descoberta, o aprendizado e o crescimento. Foi sempre com muito entusiasmo que os jovens entrevistados falaram da possibilidade de aprender coisas novas (valores, modos de conduta, maneiras de se orientar, além de informações necessárias para a vida cotidiana) e de conhecer gente nova.

Aprender nos depoimentos juvenis, no entanto, estava intimamente associado a fazer. Para os jovens entrevistados, conhecimento é prática e aprender é fazer. Daí que o desejo de aprender manifesto pelos jovens pesquisados não implicava reflexão e crítica, mas significava a aceitação da realidade e a intenção de participar dela. Na verdade, o que desejavam aprender eram informações, não só técnicas, mas também aquelas relacionadas ao comportamento, que tenham alguma utilidade imediata para a vida social. $O$ que os jovens queriam saber é como se movimentar nesse mundo. Nesse sentido, as coisas novas que devem ser aprendidas são apenas as já existentes.

Pode-se afirmar que, no limite, essa apologia da prática é também a apologia do tempo presente e o seu reverso, a rejeição à teoria, é também a negação da herança cultural originária do passado e dos esforços para perpetuá-la. Dessa forma, o conhecimento escolar, identificado com a teoria, não tem sentido em si mesmo, mas apenas como suporte para a verdadeira aprendizagem que deve acontecer no futuro, na vida lá fora: a prática.

Enquanto a escola foi identificada pelos entrevistados como o local onde se aprende apenas o básico, o trabalho era visto como o ambiente onde se pode aprender, ampliar o círculo inicial composto pelos familiares e pelo grupo de pares, além de adquirir responsabilidade. Isto é, o trabalho - ao contrário da escola - é oportunidade de crescimento e amadurecimento. $\mathrm{O}$ ambiente de trabalho é também mais organizado que a escola, com critérios e regras mais definidos e estáveis, limites mais rígidos para a conduta, atribuições e expectativas compartilhadas. Enfatizando, pois, os 
aspectos educativos do trabalho (apesar do fato de estarem exercendo funções menos qualificadas), os jovens entrevistados, em sua maioria, declararam-se satisfeitos com seus empregos.

Ao mesmo tempo, na escola, o que se destacava para os alunos era sua dimensão instrumental. A importância da escola resumia-se em oferecer o básico (conhecimentos elementares que permitam a verdadeira aprendizagem - prática - posterior) e a credencial que permite pleitear um lugar no mercado de trabalho.

Essa concepçâo instrumental, tanto do conhecimento como da escola, favorece práticas como colar e decorar matéria. Estudar transforma-se em sinônimo de decorar a matéria e não significa aprender, mas obter uma nota satisfatória. Uma vez que a escola não oferece o verdadeiro conhecimento (a prática) e que a teoria é rejeitada pelos alunos, aprender como atividade escolar não é assimilar conteúdo (apenas o básico tem uma função considerada válida), mas exercitar sem censura as manifestações individuais do pensamento (mesmo o desinformado). Isto é, na escola, os alunos valorizam apenas o relativo campo do que denominam a própria opinião. Opinião, contudo, que não se baseia no conhecimento, interpretação e reflexão acerca de uma realidade, mas apenas significa a oportunidade de alguma manifestação individual perante o professor. Estamos no reino do relativismo mais radical, em que toda afirmação é válida, uma vez que emite opinião.

Aprender na escola, portanto, seria algo que não requer nenhum tipo de esforço (como estudo, concentração, disciplina, atenção), mas seria um ato espontâneo, que "brotaria naturalmente" do organismo'. Assim, são rejeitadas as aulas expositivas, as leituras e o próprio livro, em favor dos "debates", momentos de manifestação das chamadas opiniões. Mas, por ocasião das provas escritas, as opiniões nem sempre são aceitas pelo professor (que prefere validar cópias do texto oficial a considerar o texto, por vezes desconexo, do aluno); e, diante da grande dificuldade de interpretação dos conteúdos e de uma redação coerente, tornam-se práticas correntes a "decoreba" e a cola.

$\mathrm{Na}$ relação ensino-aprendizagem na escola, o jovem aluno se coloca como aquele que deve ser resgatado, convencido, capturado pelo professor. Ele não se vê como receptor passivo ou
A crise da escola pública:

- aprender a aprender

Regina Magalhāes de Souza
Nos dias em que redigia esta página, o segundo colocado no exame da Fuvest/2000, justificando o pouco tempo que dedicava ao ato de estudar, declarava aos repónteres: ... aprender é mais importante do que estudar!, como se houvesse uma contradição entre os termos (Charâo, 2000). 
A crise da escola pública: - aprender a aprender Regina Magalhäes de Souza mero depositário de conteúdo, pois questiona o valor do conhecimento escolar, mas também não se coloca como sujeito da ação educativa. O jovem aluno se auto-representa como aquele que deve ser "guiado" pelo professor, depois de ter sido suficientemente persuadido não por meio de argumentação racional, mas pela relação, por que não dizer, afetiva que deve se estabelecer entre ambos. Ao professor, e apenas a ele, caberiam a iniciativa e a condução do processo de aprendizagem escolar.

Os depoimentos ressaltaram, portanto, a importância das relações interpessoais no processo de aprendizagem. Os jovens pareciam não querer se identificar plenamente com o papel de aluno e depositavam suas expectativas na personalidade dos professores que deviam motivá-los (cf. DUBET, 1991). Aos olhos dos jovens pesquisados, que esperavam ser resgatados pelo mestre, o bom professor era aquele que não só gosta de dar aula, mas gosta também de seus alunos. Ele deve ser amigo, dispensando atenção individual a seus alunos, deve explicar bem e saber impor o respeito. Aos alunos, para quem a escola e o conhecimento têm um sentido apenas instrumental e o convívio com os colegas é o cerne da vida escolar, cabe corresponder ou não à iniciativa do mestre.

Para os alunos, o aspecto mais importante da vida escolar é justamente o convívio com os colegas e amigos, fonte de prazer e satisfação, além de oportunidade de troca de idéias e aprendizado. $\mathrm{O}$ círculo de colegas de escola, em que não há conflito de interesses nem competição, oferece cumplicidade e apoio na realização de práticas (individuais e não coletivas) que visam o êxito na vida escolar (como a cola, por exemplo). Tais práticas, que mais parecem atos de "cumplicidade" e não exatamente "solidariedade", também não anunciam a existência de um espírito de grupo ou uma consciência coletiva. Embora se possa contar com o apoio dos colegas, as soluções encontradas são individuais e não coletivas.

Além disso, a sociabilidade juvenil no ambiente escolar não é estimulada, patrocinada, nem sequer considerada pela escola, realizando-se de forma independente de qualquer ação educativa. Dessa forma, não há uma verdadeira integração dos alunos com a escola, reduzida a mera organização emissora de certificados, alheia à vida juvenil (cf. DUBET, 1991). 


\section{Uma redefinição das funções da escola}

Creio que a escola pública nos dias de hoje caracteriza-se pela ausência de fato de um projeto educativo que lhe dê substância e fundamento (os próprios alunos consideram o ensino fraco) e pela fragilidade da integração de seus alunos com a organização. Destinada às camadas mais pobres da população, uma vez que a elite há muito foi procurar alguma qualidade na rede privada de ensino, seu papel imediatamente reconhecivel tem sido apenas o de oferecer a credencial que permite o ingresso no mercado de trabalho.

De maneira geral, $o$ grande requisito exigido pelo mercado de trabalho tem sido o certificado de escolaridade (em níveis cada vez mais altos) e não os conhecimentos que lhe correspondam. Parece que o nível de escolaridade tem sido tomado pelo mercado mais como indicador da socialização do indivíduo do que pré-requisito para o exercício das funções (Fundação SEADE/DIEESE, 1994). No entanto, creio que a escola também não esteja mais correspondendo a essa expectativa do mercado, pelo menos nos moldes tradicionais. $\mathrm{O}$ disciplinamento da mão-de-obra, outrora ocorrido no ambiente escolar, onde se aprendia o respeito à hierarquia, a observância de horários $\mathrm{e}$ regras e onde se incorporavam os valores do trabalho, já não acontece mais na escola.

A escola pública dos dias de hoje está sofrendo uma profunda transformação, em sintonia, certamente, com a (também transformada) cultura contemporânea. A escola do passado, ou a imagem ideal da escola tradicional, uma instituição com objetivos claramente definidos - numa palavra, de perpetuar uma cultura por meio da formação e socialização das novas gerações -, está em crise. Afirmar que a escola está em crise não significa anunciar o seu fim, mas significa dizer que os padrões tradicionais estão sendo rompidos e que os objetivos do passado não mais conseguem se realizar. E creio que o indicador mais visivel dessa transformação da escola seja justamente o desmonte do poder disciplinar. Se "a diferença essencial entre a escola da Idade Média e o colégio dos tempos modernos reside na introdução da disciplina"
A crise da escola pública:

- aprender a aprender

Regina Magalhảes de Souza 
A crise da escola pública: - aprender a aprender Regina Magalhāes de Souza
(ARIÈS, 1981: 191), creio que o aspecto distintivo da escola pública (especificamente a da cidade de São Paulo) dos dias de hoje é justamente a instabilidade do poder disciplinar. É ainda Ariès (1981) quem afirma:

"A disciplina escolar teve origem na disciplina eclesiástica ou religiosa; ela era menos um instrumento de coerção do que de aperfeiçoamento moral e espiritual, e foi adotada por sua eficácia, porque era a condição necessária do trabalho em comum, mas também por ser valor intrínseco de edificação $e$ ascese." (p.191)

Na escola dos dias de hoje, os dispositivos disciplinares se mantêm, mas seguem esvaziados de seu conteúdo educativo original: de aperfeiçoamento moral e espiritual, edificação e ascese ou meio de assimilação de conhecimento. A disciplina escolar visava aperfeiçoar a relação entre obediência e desenvolvimento de habilidades, de tal modo que, quanto mais obediente, mais útil o corpo humano e vice-versa (cf. FOUCAULT, 1997). Hoje, a formação do aluno não parece ser mais preocupação da escola e suponho que a única justificativa para a permanência dos dispositivos disciplinares seja a tentativa de viabilizar o funcionamento do estabelecimento escolar. Ora, com suas bases minadas, o poder disciplinar segue oscilante no interior do estabelecimento e perde justamente suas características de "disciplina": ordem, regularidade, hierarquia, sistematização, rigidez.

Esvaziada, portanto, de seus objetivos e de suas funções tradicionais, a escola em crise tenta continuar funcionando por meio de procedimentos legais e burocráticos, regras e normas que, sem conexão com qualquer intenção educativa, apenas visam a regulação do estabelecimento. A socialização dos jovens alunos tem ocorrido justamente no âmbito da regulação do sistema, em que se deparam com a oportunidade e a necessidade de se ajustarem à instabilidade das regras e se desvencilharem dos obstáculos do cotidiano escolar. Esse ajustamento ou adaptação não se dá pela via da interiorização de hábitos, valores e modelos 
de conduta, mas pelo exercício do pensamento instrumental, que avalia racionalmente os meios para a consecuçâo de um fim particular. E mais: no cotidiano escolar, os meios transformam-se em fins em si mesmos, na medida em que a importância atribuída à nota, à vestimenta ou ao crachá segue desconectada do objetivo de aprender e até mesmo da finalidade de obter somente um certificado.

Nessas circunstâncias, a escola não é um lugar agradável para os alunos. Eles não gostam da escola e não querem se identificar com um estabelecimento sobre o qual sempre têm muitas críticas a fazer. A maior parte das queixas referiu-se à gestão e administração do estabelecimento, sendo que, além da precariedade das instalações, falta de aulas e desempenho da direção, o grande problema apontado pelos alunos foi a desorganização. A existência de inúmeras regras de funcionamento e procedimentos disciplinares não garante o funcionamento adequado do estabelecimento, mas, pelo contrário, a instabilidade e a possibilidade sempre presente de transgressão e negociação dessas mesmas regras e procedimentos levam a uma situação percebida pelos alunos como de muita burocracia para pouca ordem!

As regras estabelecidas com veemência nos primeiros dias de aula são esquecidas e relembradas ao acaso durante o ano letivo, quando são retomadas com estardalhaço para serem afrouxadas em seguida. A transgressão não traz maiores conseqüências e as ameaças de punição não se efetivam. $O$ maior ou menor cumprimento da regra também depende do funcionário ou professor envolvido, mais ou menos disposto a negociar. E, por outro lado, a tentativa de imposição de qualquer norma de conduta ou de funcionamento também não surte efeito, uma vez que os alunos não querem ser mandados. $\mathrm{O}$ autoritarismo puro e simples não mais funciona, pois os detentores dos mecanismos de disciplina e punição não conseguem mais exercer poder sobre os alunos. Contudo, ao mesmo tempo em que não aceitam imposição de nenhum tipo e burlam as regras existentes, os alunos sentem-se incompreendidos, sem direitos e sem poder. Reclamam que não são ouvidos pela escola. Isto é, o esvaziamento do poder disciplinar no interior da escola não
A crise da escola pública: - aprender a aprender Regina Magalhâes de Souza 
A crise da escola pública: - aprender a aprender Regina Magalháes de Souza
${ }^{2} \mathrm{Da}$ mesma forma, a obediência às regras impostas pela disciplina não significa a incorporação de um sistema democrático de direitos e deveres ou a apreensão do significado da lei e da justiça. Disciplina significa dominaçâo e disparidade, radicalmente contrárias à democracia e ả justiça (cf. Foucault, 1997). significa que ela tenha se tornado uma instituição democrática, atenta às necessidades e direitos dos alunos ${ }^{2}$, mas simplesmente significa que ela abdicou do seu objetivo de educar e formar os indivíduos.

Essa situação é motivo de grande insatisfação. Os alunos queixaram-se da ausência de regras claras, predefinidas e estáveis, com critérios justos que não estabeleçam nenhuma discriminação. Os alunos não vêem sentido nas regras existentes, que não têm legitimidade, são arbitrárias e cuja única função é tentar manter funcionando uma escola em crise de autoridade. Na escola, burlar uma regra não significa infringir uma lei legitimamente aceita, nem contestar o poder vigente, mas apenas escolher o melhor meio para atingir um objetivo imediato e particular. É uma crise moral que acompanha a crise institucional, pois não há mais certo e errado, mas apenas meios mais ou menos eficientes para atingir um fim (colar, providenciar falsos atestados, pular o muro, inventar uma história...). Creio que a escola pode estar formando indivíduos que seguirão descrentes da lei, da justiça e da ordem, que no futuro acreditarão que toda regra é arbitrariedade e burocracia inútil (cf. COSTA, 1988; 1995).

Os alunos criticaram a desordem, a desorganização, ou seja, a instabilidade na regulação do estabelecimento. No entanto, eles tinham dificuldade em assumir as responsabilidades implícitas na observância de regras democráticas. Pode-se afirmar que a escola, de fato, não tem formado cidadãos aptos a uma vida social democrática, mas sim indivíduos que, ao se defrontar com a instabilidade institucional, desenvolvem estratégias racionalmente concebidas para assegurar seus interesses particulares, num universo moral em que não há lei nem autoridade. Uma vez que não vêem como alterar uma situação tida como inevitável, a crítica é seguida não pela atitude inconformada e transformadora, mas pela adaptação ao caos e à desordem.

À perda de autoridade da escola os alunos respondem não com a rebelião, mas com o desprendimento. Desestruturada, a escola não consegue constituir-se em ponto de referência para a contestação, pois não representa ideais em nome dos quais ou contra os quais se deva lutar. O distanciamento é também o 
mecanismo de defesa individual frente à precariedade e à pobreza da escola: o aluno não quer se identificar com a escola que freqüenta. Ele tenta salvar uma auto-imagem negativa (grande parte dos jovens que responderam ao questionário identificou os próprios alunos - indisciplinados, desinteressados - como o maior problema da escola) afastandose da escola. Insatisfeito, o jovem aluno denuncia a situação da escola, mas, sentindo-se impotente para revertê-la, ele se ajusta às circunstâncias, manipulando e dominando as forças em jogo. No entanto, a possibilidade de manipular o cotidiano escolar a seu favor apenas faz crescer no aluno a sua descrença na autoridade e na escola.

Esse tipo de conduta observado entre os jovens alunos parece fundar-se em algo semelhante à visão cínica de mundo (cf. Costa, 1988), segundo a qual a realidade existente é tomada como norma e ideal e, apesar disso, criticada. Trata-se, no entanto, de uma crítica aparente que justifica as ações individuais em função das circunstâncias. E, uma vez que a realidade é tida como inevitável, para sobreviver resta ao indivíduo a conduta de adaptação ou ajustamento (cf. HORKHEIMER, 1976).

Afirmar que os jovens alunos agiam no sentido da inserção social mediante um comportamento de adaptação ou ajustamento não significa, pois, identificar sua ação com o simples conformismo ou apatia, categorias presentes na classificação de setores da juventude de décadas anteriores, que se opunham ou se omitiam diante de projetos de transformação da sociedade. Em primeiro lugar, porque a conduta de adaptação exibida pelos jovens pesquisados não se originava da aceitação de uma realidade com a qual (pelo menos formalmente) se estava de acordo. Pelo contrário, a realidade do ambiente escolar é fonte de insatisfação e alvo de inúmeras queixas e, no entanto, tida como inevitável. Impotentes que são para mudá-la, os alunos não vêem outra alternativa senão a adaptação ou ajustamento.

Em segundo lugar, a conduta de adaptação vai além da simples assimilação da realidade, consistindo numa ação praticada pelo indivíduo, que manipula estratégias e calcula racionalmente meios e fins. Os jovens alunos não constituem meros receptores de
A crise da escola pública:

- aprender a aprender Regina Magalhāes de Souza 
A crise da escola pública: - aprender a aprender Regina Magalhães de Souza papéis que devem desempenhar, mas exibem um certo domínio sobre as regras e sobre a atitude de funcionários, professores e colegas, enfim, mantêm um "certo" nível de manipulação da realidade que os cerca.

Por um lado, é certo que a adaptação e o cinismo excluem a possibilidade de uma ação transformadora. Por outro, há que se observar que os jovens alunos conhecem muito bem e sofrem os "efeitos" da crise da escola, mas não conseguem decifrar a própria crise. Cada aluno é capaz de enumerar um amontoado de problemas que tem o estabelecimento escolar, mas nenhuma dessas queixas em particular, nem seu conjunto, é capaz de explicar de uma vez por todas a situação caótica em que se encontra a escola. No fundo, a crise da escola permanece intangivel e indecifrável, o que permite apenas, como foi dito, um "certo" nível de manipulação do cotidiano escolar ou a habilidade para lidar apenas com os efeitos imediatos dessa realidade (cf. CARDOSO, 1997).

Essa manipulação do cotidiano ocorre justamente no âmbito da regulação do estabelecimento, cuja característica é a instabilidade. Pode-se levantar a questão da possibilidade de uma real ação transformadora num ambiente marcado pela instabilidade e pela indiferenciação, em que não há referências para a mudança. A esse respeito, vale lembrar as palavras de Hannah Arendt (1973):

"Nenhuma civilização - o artefato humano para abrigar gerações sucessivas - teria sido jamais possivel sem uma estrutura de estabilidade que proporcionasse o cenário para o fluxo de mudança. Entre os fatores estabilizantes, vêm em primeiro lugar os sistemas legais que regulam nossa vida no mundo e nossas questões diárias uns com outros..." (p. 72)

A escola de ensino médio não mais disciplina a mão-de-obra (nem a qualifica para o mercado, como, aliás, gostariam seus alunos). Ela também não ensina nem teoria nem prática (mantendo a terminologia dos alunos entrevistados), mas habilidades. O próprio documento que instituiu as Diretrizes Curriculares Nacionais para 
o Ensino Médio (em junho de 1998, sete meses depois da coleta de dados nos dois estabelecimentos escolares) enfatiza o desenvolvimento das habilidades, chamadas "competências básicas", sob os auspícios do preceito "desenvolvimento da capacidade de aprender e continuar aprendendo" (artigo $4^{\circ}$ da Resolução CEB n. ${ }^{\circ} 3$ ).

$\mathrm{E}$, baseada na leitura dos resultados da investigação realizada, levanto a hipótese de que a principal habilidade desenvolvida na escola pública hoje seja justamente a capacidade de "aprender a aprender" não os conteúdos das ciências humanas, fisicas, biológicas ou da filosofia, arte e religião, mas aprender a identificar os meios mais adequados para a sobrevivência em condições sociais mutáveis. É possível que a ação educativa, ainda que de maneira não intencional, resuma-se, nos dias de hoje, no desenvolvimento da capacidade do indivíduo de, pelo exercício do pensamento instrumental, adaptar-se a um meio social de regras instáveis.

A hipótese inicial do trabalho de pesquisa era a de que a escola pública teria perdido não só seu potencial educativo (na medida em que não assegura a transmissão de uma cultura), mas também seu potencial socializador (na medida em que não mais inculca hábitos, valores, modos de conduta etc.). A idéia implícita nessa hipótese era a de que a escola não mais estaria servindo como fator de reprodução das relações de produção (lembrando Althusser) ou de conservação social (expressão de Bourdieu). Uma vez que as classes populares, que freqüentam o sistema escolar público, há muito também não têm acesso à cultura erudita, a escola (que também não oferece adequada preparação para o mercado de trabalho) continuaria existindo apenas como uma formalidade ou um resquício de épocas passadas.

Contudo, os resultados da pesquisa entre os jovens alunos sugerem que o processo de socialização, que se realizaria no âmbito da regulação do estabelecimento, não seria conseqüência de uma intenção educativa (explícita ou não, de "disciplinar", "aprimorar o caráter", "moldar a personalidade" ou "transmitir valores"). A socialização não se daria como um processo de interiorização de
A crise da escola pública:

- aprender a aprender

Regina Magalháes de Souza 
A crise da escola pública:

- aprender a aprender

Regina Magalhāes de Souza hábitos e valores, mas como o desenvolvimento da capacidade de "aprender a aprender", requisito essencial para a adaptação a um meio instável. É ao se deparar com as regras, cujo único objetivo é manter em funcionamento o estabelecimento escolar, que o aluno se socializaria ou, em outras palavras, se ajustaria ao meio social. Diante da instabilidade das regras e da desestabilização da instituição, o jovem aluno aprenderia a se ajustar, desenvolvendo estratégias para contornar os obstáculos do cotidiano escolar e alcançar o êxito em seus propósitos particulares.

Nesse sentido, é possível afirmar que, mesmo sem uma intenção pedagógica, a escola estaria promovendo o ajustamento do individuo à ordem social. É possivel que as estratégias desenvolvidas pelos alunos, ao se defrontarem com a instabilidade das regras da vida escolar, fundamentem a conduta requerida para a inserção adequada no meio social mais amplo. A escola, nos dias de hoje, não parece um ambiente que valoriza o esforço pessoal, mas a habilidade em manipular situações. A negação do esforço e do trabalho está presente na própria concepçâo de aprender como um ato espontâneo, que se opõe ao ato de estudar (identificado com a "decoreba"). $\mathrm{Na}$ escola, a transgressão das regras é encarada apenas como a escolha do meio mais eficiente para a obtenção de um fim particular. Enfím, é a "lei da sobrevivência" o que prevalece. Essa maneira de pensar e agir, encontrada entre os jovens alunos, parece ser a mesma que predomina na sociedade brasileira dos dias de hoje, em que reinam o casuismo, a impunidade, o desrespeito com o consumidor, contribuinte, cidadão, e em que leva vantagem justamente aquele que perdeu as ilusões e não mais acredita na lei, na justiça e na ordem.

Numa palavra, creio que não seja mais o disciplinamento da força de trabalho o que promove a escola, mas a adaptação do individuo à instabilidade, ausência de autoridade e de critérios, prevalência dos interesses individuais sobre os coletivos, descrédito da justiça e da lei que caracterizam a vida contemporânea. Ainda que com forma e conteúdo novos, a escola pública continuaria mantendo uma importante dimensão socializadora, de ajustamento ao meio social, portanto. 
Abstract: The main purpose of this work was to investigate what kind of subject is being formed by the public school nowadays, considering the deep cultural changes that are happening. The public school is in a moment of crisis and isn't being able to articulate an effective educational project and isn't preparing the youngsters for work by transmitting technological know-how or by shaping adequately their behavior. Two public high schools in the capital of São Paulo have been investigated, where the students took part of collective interviews and answered to a questionnaire. The education school was offering consisted only of the ability of 'learning how to learn', that is developing the capability of adapting oneself to a social life in which the keynote is the lack of authority, criteria and values crisis.

Keywords: education; public school; high school; youth; contemporary culture.
A crise da escola pública: - aprender a aprender Regina Magalhäes de Souza

\section{Bibliografia}

ABRAMO, Helena Wendel. Cenas juvenis. São Paulo, Scritta/ANPOCS, 1994.

ALTHUSSER, Louis. Ideologia e aparelhos ideológicos do Estado. Lisboa, Presença, 1970.

ARENDT, Hannah. A crise na educação. In: Entre o passado e o futuro. São Paulo, Perspectiva, 1992a, pp. 221-47.

Desobediência civil. In: Crises da república. São Paulo, Perspectiva, 1973, pp. 49-90.

Que é autoridade? In: Entre o passado e o futuro. São Paulo, Perspectiva, 1992 b, pp. 127-87.

ARIĖS, Philippe. História social da criança e da familia. Rio de Janeiro, Guanabara Koogan, 1981.

BOURDIEU, Pierre. A escola conservadora: as desigualdades frente à escola e à cultura. In: NOGUEIRA, Maria Alice \& CATANI, Afrânio (orgs.). Escritos de educação. Petrópolis, Vozes, 1999, pp. 39-64.

CARDOSO, Irene. A narrativa silenciada. In: CARDOSO, Irene \& SILVEIRA, Paulo (orgs.). Utopia e mal-estar na cultura: perspectivas psicanaliticas. São Paulo, Hucitec, 1997, pp. 169-96. 
A crise da escola pública:

- aprender a aprender

Regina Magalháes de Souza
CHARÃO, Cristina. Fuvest divulga lista de aprovados no vestibular. $O$ Estado de S. Paulo, $05 /$ fevereiro/2000, p. A12.

COELHO, Cláudio Novaes Pinto. A cultura juvenil de consumo e as identidades sociais alternativas. Comunicação apresentada no XXI Congresso da Associação Latino-Americana de Sociologia / ALAS, São Paulo, 1997.

CONSELHO NACIONAL DE EDUCAÇÃO. Resolução CEB n. ${ }^{\circ} 3$, de 26/junho: institui as Diretrizes Curriculares Nacionais para o Ensino Médio. Revista de Educação. São Paulo, (10): 68-72, 1998.

COSTA, Jurandir Freire. A ética e o espelho da cultura. Rio de Janeiro, Rocco, 1995.

Narcisismo em tempos sombrios. In: BIRMAN, Joel (org.). Percursos na história da psicanálise. Rio de Janeiro, Taurus, 1988, pp. 151-74.

DUBET, François. Les lycéens. Paris, Éditions du Seuil, 1991.

DUBET, François \& MARTUCCELLI, Danilo. Al 'école: sociologie del'expérience scolaire. Paris, Éditions du Seuil, 1996.

FERNANDES, Angela Viana Machado. Diretrizes curriculares nacionais para o ensino médio: é possivel superar a histórica dualidade? Revista de Educação. São Paulo, (10): 21-28, 1999.

FORACCHI, Marialice Mencarini. A juventude na sociedade moderna. São Paulo, Pioneira, 1972.

FOUCAULT, Michel. Vigiar e punir: nascimento da prisão. Petrópolis, Vozes, 1997.

FRANCO, Maria Laura P. Barbosa. Avaliação e redefinição da politica do ensino de $2^{\circ}$ grau. Cadernos Cedes. Campinas, (20): 26-35, 1988.

O ensino médio no Brasil e a nova LDB. Revista de Educação. São Paulo, (10): 38-42, 1999.

FUNDAÇÃO SEADE - DIEESE. Educação formal e mercado de trabalho. Suplemento do boletim da Pesquisa de Emprego e Desemprego na Grande São Paulo n. ${ }^{\circ} 112$. São Paulo, 1994.

HORKHEIMER, Max. A revolta da natureza. In: Eclipse da razão. Rio de Janeiro, Labor, 1976, pp. 103-38. 
IANNI, Octavio. O jovem radical. In: Industrialização e desenvolvimento social no Brasil. Rio de Janciro, Civilizaçâo Brasileira, 1963, pp. 159-79.

JORNAL DE PSICOLOGIA. Novos parâmetros retiram psicologia do ensino médio. São Paulo, Conselho Regional de Psicologia-CRPSP, ano 17, n. ${ }^{\circ} 18$, set./ out./1999, p. 14.

KUENZER, Acácia Zeneida. O ensino médio no contexto das políticas públicas de educação no Brasil. Revista Brasileira de Educação. São Paulo, (4): 77-95, 1997.

LEI FEDERAL n. ${ }^{\circ}$ 9.394, (1996). Diretrizes e Bases da Educaçâo Nacional, aprovada na Câmara Federal em 17/12/1996 e sancionada pelo Presidente da República em 20/12/1996. Brasilia (mimeo).

MARKS, Cecilia. Crise de identidade: mudanças aprovadas pelo Conselho Nacional de Educação pretendem dar novo rumo ao ensino médio, Educação. São Paulo, (207): 14-16, 1998.

MISCHE, Ann. De estudantes a cidadãos: redes de jovens e participação política. Revista Brasileira de Educação. Sào Paulo, (5-6):134-50, 1997.

NOSELLA, Paolo. A escola brasileira no final de século: um balanço. In: FRIGOTTO, Gaudêncio (org.). Educação e crise do trabalho: perspectivas de final de século. Petrópolis, Vozes, 1998, pp. 166-88.

SARLO, Beatriz. Cenas da vida pós-moderna: intelectuais, arte e vídeo-cultura na Argentina. Rio de Janeiro, UFRJ, 1997.

SPÓSITO, Marilia Pontes. Estudos sobre juventude em educação. Revista Brasileira de Educação. São Paulo, (5-6): 37-52, 1997.

VELHO, Gilberto. A dimensão cultural e politica dos mundos das drogas. In: ZALUAR, Alba (orga.). Drogas e cidadania: repressão ou redução de riscos. São Paulo, Brasiliense, 1994, pp. 23-29.
A crise da escola público:

- aprender a aprender

Regina Magalháes de Souza 